\title{
Technology, Production, and Socio-Economic Indicators at the Macro Level: A Statistical Analysis of the Chinese Regions
}

\author{
Yanqing Jiang ${ }^{1} \&$ Chunyang Wan ${ }^{1}$ \\ ${ }^{1}$ School of Economics and Finance, Shanghai International Studies University, Shanghai, P. R. China \\ Correspondence: Yanqing Jiang, School of Economics and Finance, Shanghai International Studies University, No. \\ 1550 Wenxiang Rd., Shanghai 201620, P. R. China
}

Received: June 30, 2014

Accepted: July 14, 2014

Available online: August 4, 2014

doi:10.11114/set.v1i2.452

URL: http://dx.doi.org/10.11114/set.v1i2.452

\begin{abstract}
This study contains a statistical analysis exploring the interrelationships between technology, production and various socio-economic variables in the context of China's regional macroeconomy. We focus on empirically examining how technology at the macro level is interrelated to production, output, and various macro-level socio-economic indicators. Our statistical analysis shows that a higher level of technology is always associated with socio-economically desirable outcomes on the various chosen macro-level indicators. However, the causality may run bi-directionally. Our empirical results also show that even after the partial effects of all the other macro-level variables are netted out, that is, even when the indirect effects of technology are not considered, the remaining direct effect of technology is still shown to play a very crucial role in determining labor productivity in the production process at the macro level.
\end{abstract}

Keywords: technology, production, socio-economic indicator, statistical analysis, China

\section{Introduction}

The increasing role of technology in influencing socio-economic development can be seen in many aspects of a modern society. However, to date, socio-economic development in China still relies much more heavily on the advantages of low cost labor than on the utilization of advanced technology. This study focuses on a statistical analysis of the interrelations between technology, production and various socio-economic variables in the context of China's regional economy at the macro level. After designing a comprehensive macro-level measure for technology, we empirically explore how technology is interrelated to production, output, and various macro-level socio-economic variables through our statistical analysis.

This study is structured as follows. Section 2 provides an overview of the important role of technology from a development perspective. In Section 3, we construct a feasible measure for technology at the macroeconomic level. In Section 4, based on the measure of technology we have constructed in the preceding section, we perform our statistical analysis to empirically explore the interrelationships between technology, production and various socio-economic variables in the context of China's regional macroeconomy. Section 5 extends our empirical analysis by introducing more data and related methodology. Finally, Section 6 concludes this study.

\section{An Overview: Technology from a Development Perspective}

Any country or region that creates, distributes, and applies technology and knowledge to generate social wealth gives rise to a network society in which the ability to access technology and join learning-intensive relations determines the socio-economic position of individuals and production units, as well as the general performance of the macroeconomy (Clarke, 2001; Laszlo and Laszlo, 2007). Technological advancements in society call for the incessant need to create and manage intangible assets (technology and knowledge) that do not depreciate but increase in value over time. This incessant need has fostered the formation of technology management, which provides necessary means to generate, distribute, and utilizes technology (knowledge) in ways that increase value to business activities and open new opportunities for enterprises (Clarke, 2001).

Technology-led socio-economic development is an extension of the technology management agenda (Laszlo and Laszlo, 2007). As technology management deepens, it is developing into a strategic management approach that is applied to purposeful social-economic organizations in general (Carrillo, 2002). Technology-led development implies the 
application of technology management to development issues, and is therefore a powerful strategy for countries or regions to seek economic prosperity and social harmony. On the one hand, technical knowledge is directly useful in bring about economic returns (Lever, 2002). On the other hand, technology-led development also aims to foster the human capital (knowledge and skills) of people as a means for individual and social development (Ovalle, Marquez, and Salomon, 2005). Obviously, these two main functions of technology-led development are mutually supportive. Accumulation of knowledge and human skills brings about more creativity, innovation, and entrepreneurship that promote socio-economic outcomes while economic prosperity and social harmony offer individuals more opportunities to accumulate knowledge and skills.

The growing role played by technology in issues associated with socio-economic development is seen in many aspects of a modern society. Investment in human capital and technology, such as expenditures on education, job training, and research, now accounts for over ten percent of total gross domestic product (GDP) for OECD countries as a whole. One key feature of technology-led development is the accelerated incorporation of knowledge into productive activities related to both tangible goods and intangible services: knowledge become embedded in production processes in a wide variety of ways, ranging from on-the-job "learning by doing" by workers to formal procedures of investment in advanced technology, knowledge application, and labor training. Similarly, embodied knowledge is playing a more and more important role in areas such as business consulting, services education and training, and medical diagnosis and treatment. The increasing technology intensity in socio-economic activities is determined not only by the increasing technology intensity in individual goods and services, but also by the growing importance of goods and services that rely on embodied knowledge. In this sense, technology-led development relies on significant and constant changes in the industrial structure of developing countries. The shift of the shares from the traditional labor-based goods industries to the technology and human capital based industries with respect to the composition of employment or output is an important feature of technology-led development (Sheehan, 1999).

To date, socio-economic development in China is still based much more heavily on the advantages of low cost labor than on the utilization of advanced technology. To China, one major challenge brought about by the global waves of technology revolution is how to build an industrial structure that could make fuller use of technology developed both abroad and within the country. In addition, development in an open, unified, technology-intensive global economy generates continuous pressures on the increasing regional and sectoral disparities within China.

Inflows of foreign direct investment (FDI) have been widely seen as an indispensable element in accounting for China's socio-economic development. The colossal success of China's economic reform and the growth of the country's innovation capacity are partly attributable to the policy of attracting and retaining FDI (Buckley, Clegg, and Wang, 2002; Liu and Wang, 2003). However, some argue that with the huge influx of FDI China has become overly dependent on foreign technology (Gilboy, 2004). Seeing this, the Chinese government, on the one hand, began to regulate FDI, and on the other hand, enhanced support to innovation activities in domestic enterprises (Huang and Soete, 2007). To finance innovation, China also strived to build a well-functioning financial system, and especially a venture capital system, to support technology-based enterprises.

Apart from FDI, trade is another mechanism through which Chinese enterprises can tap into global technology. Imported high-tech products and capital goods embody a tremendous amount of technology. Also, foreign trade brings salutary spillovers to Chinese enterprises and the Chinese economy. However, while China has been quite active in introducing foreign technology embodied in tangible goods, it has been less active in importing disembodied technology (such as patents, which normally incurs royalties or licensing fees). Low imports of disembodied technology may hamper the efficient use of technological knowledge. Although importing high-tech products and capital goods is an important way of acquiring foreign technology, the accompanying knowledge support (disembodied technology) should also be acquired in order to maximize the efficiency of technology investment.

All in all, China needs to fully exploit the rapidly growing global technology to accelerate its own socio-economic development and facilitate its transition toward a technology-based, sustainably growing economy. The challenge lies in striking a sensible balance between technology creation and technology acquisition (Dahlman and Aubert, 2001). This in turn implies adapting foreign technology to the context of China's socio-economic development and meanwhile budgeting for research and development $(\mathrm{R} \& \mathrm{D})$ activities to create technology within China.

\section{Measuring Technology at the Macro Level}

We need to design variables to measure "technology" at the macroeconomic level. Technology in this sense is not directly measurable because it does not refer to any specific technology in any specific industrial field. Instead, it is expected to refer to the general technological level of productive activities in a given economy (i.e. a Chinese region in the current study). Therefore, we need to find proxy or indicator variables for technology at the macro level. The variables, according to their functions, can be roughly divided into two groups, one measuring technology creation and the other measuring technology acquisition. Considering severe data constraints, we will only focus on a limited scope 
of chosen variables.

The group of variables we choose to measure technology creation is associated with regional statistics on $\mathrm{R} \& \mathrm{D}$ activities and patents of industrial enterprises above a designated size. These statistics include annual regional data on per capita full-time equivalent of R\&D personnel (in person-years per capita), per capita expenditure of funds on R\&D (in 10 thousand RMB yuan per capita), the number of per capita R\&D projects (in units per capita), the number of applications for patents per capita (in pieces per capita) and of which the number of applications for patented inventions per capita (in pieces per capita), as well as the number of patented inventions per capita currently in force (in pieces per capita). R\&D personnel refers to the number of people engaged in research, management and supporting activities of $\mathrm{R} \& \mathrm{D}$, including people in project teams and in the management of related activities of enterprises as well as supporting staff providing direct service to the research projects. This indicator reflects the size of personnel engaged in R\&D activities with independent intellectual property. ${ }^{1}$ Full-time equivalent of R\&D personnel refers to the sum of the full-time staff and the full-time equivalent of part-time staff converted by workload. ${ }^{2}$ Expenditure of funds on R\&D refers to the real expenses of surveyed units on their own R\&D activities (such as basic research, application study, test and development) including direct expenses on R\&D activities, indirect expenses of management and services on R\&D activities, expenditure on capital construction and material processing by others (but excluding the expenditure on production activities, return of loan, and fees transferred to cooperated and entrusted agencies on R\&D activities). The number of R\&D projects (or subjects) refers to the number of R\&D projects (subjects) set up and implemented at the reference year, and the number of R\&D projects (subjects) set up in former years and under implementation, including the projects (subjects) finished and failed at the reference year, excluding the projects (subjects) implemented by others through entrustment. Patented inventions refer to new technical proposals to the products or methods or their modifications that have been granted the patent right. This is a universal core indicator reflecting technologies with independent intellectual property. ${ }^{3}$

To get a feel for the cross-sectional ranges and variations of the above-mentioned R\&D indicators, we present the basic descriptive statistics for these indicators across 31 provincial-level regions in China for an arbitrarily chosen year (which is 2012). The descriptive statistics are summarized in Tables 1 and 2. In the upper section of Table 1, we present the means, standard deviations, and minimal and maximal values of the six indicators. Even a cursory look at the statistical characteristics of the variables in this table would reveal the great interregional disparity in R\&D activities across the different Chinese regions. In the upper section of Table 2, we present the pair-wise correlations between the six indicators (temporarily ignoring the two variables $X_{1}$ and $X_{2}$ in the table, which will be explained later). Unsurprisingly, the six variables $\left(V_{1}\right.$ through $\left.V_{6}\right)$ all exhibit very high positive correlations between one another.

Table 1. The means, standard deviations, and minimal and maximal values of the variables in 2012

\begin{tabular}{cccccc}
\hline Variable & Obs & Mean & Std. Dev. & Min & Max \\
\hline$V_{1}$ & 31 & 14.16566 & 13.18542 & 0.252584 & 43.21506 \\
$V_{2}$ & 31 & 482.0095 & 467.9452 & 17.26741 & 1810.625 \\
$V_{3}$ & 31 & 1.97288 & 2.051914 & 0.078018 & 8.535542 \\
$V_{4}$ & 31 & 3.183859 & 3.674693 & 0.058514 & 12.4161 \\
$V_{5}$ & 31 & 1.165881 & 1.403655 & 0.055263 & 4.986227 \\
$V_{6}$ & 31 & 1.767576 & 2.259219 & 0.209604 & 7.861053 \\
\hline$X_{1}$ & 31 & 0.314293 & 0.368994 & 0.038587 & 1.440863 \\
$X_{2}$ & 31 & 0.290096 & 0.324504 & 0.027101 & 1.35797 \\
\hline
\end{tabular}

$V_{1}$ is the regional full-time equivalent of $\mathrm{R} \& \mathrm{D}$ personnel per capita (in person-years per capita). $V_{2}$ is regional expenditure of funds on R\&D per capita (in 10 thousand RMB yuan per capita). $V_{3}$ is the regional number of R\&D projects per capita (in units per capita). $V_{4}$ is the regional number of applications for patents per capita (in pieces per capita). $V_{5}$ is the regional number of applications for patented inventions per capita (in pieces per capita). $V_{6}$ is the

\footnotetext{
${ }^{1}$ Definitions of this and the following statistical indicators come from the corresponding explanatory notes provided by the officially published China Statistical Yearbook (various issues).

2 For instance, if there are three full-time researcher and two part-time workers with 20 percent and 70 percent of working hours respectively on $R \& D$ activities, the full-time equivalent is then $3+0.2+0.7=3.9$ person-years. This is an internationally comparable indicator of $R \& D$ manpower input.

${ }^{3}$ Patent (patent right) refers to the exclusive right of ownership by the inventors or designers for the creation or invention, given from the patent office after due process of assessment and approval in accordance with the patent law. Patents are granted for inventions, utility models and designs.
} 
regional number of patented inventions currently in force per capita (in pieces per capita). $X_{1}$ is regional trade-to-GDP ratio calculated based on "Total Value of Imports and Exports by Location of China's Foreign Trade Managing Units". $X_{2}$ is regional trade-to-GDP ratio calculated based on "Imports Value of Commodities by the Places of Their Destination and Exports Value of Commodities by the Places of Their Origin in China".

Table 2. Pair-wise correlations between the variables in 2012(correlation coefficient matrix)

\begin{tabular}{ccccccccc}
\hline & $V_{1}$ & $V_{2}$ & $V_{3}$ & $V_{4}$ & $V_{5}$ & $V_{6}$ & $X_{1}$ & $X_{2}$ \\
\hline$V_{1}$ & 1 & & & & & & & \\
$V_{2}$ & 0.9444 & 1 & & & & & & \\
$V_{3}$ & 0.9389 & 0.9551 & 1 & & & & & \\
$V_{4}$ & 0.9467 & 0.9035 & 0.9277 & 1 & & & & \\
$V_{5}$ & 0.8777 & 0.8789 & 0.8393 & 0.9215 & 1 & & & \\
$V_{6}$ & 0.8847 & 0.8631 & 0.8082 & 0.9074 & 0.9831 & 1 & & \\
\hline$X_{1}$ & 0.7302 & 0.737 & 0.6664 & 0.8114 & 0.9135 & 0.9148 & 1 & \\
$X_{2}$ & 0.812 & 0.7972 & 0.7152 & 0.7978 & 0.8196 & 0.8767 & 0.8653 & 1 \\
\hline
\end{tabular}

All the variables in this table are defined the same as in Table 1.

The aforementioned variables are indicator variables for regional efforts and performances of technology creation. We now turn to a discussion of measures for technology acquisition. Direct data on technology acquisition that are complete and consistent are hard to come by. Therefore, we resort to proxy and indicator variables for representing regional technology acquisition. We argue that regional openness to foreign trade and FDI may serve as a good proxy or indicator variable for regional technology acquisition. On the one hand, regional exposure to international economic activities (such as foreign trade and FDI) undoubtedly facilitates technology spillovers from abroad, which is in itself a crucial influencing factor of regional technology acquisition. On the other hand, we should note that social infrastructure is of critical importance in determining both technology creation and technology acquisition. This social infrastructure is in turn determined by underlying institutions and government policies. A favorable social infrastructure gets the price system right so that individuals capture the social returns to their actions as private returns. The ideal measure of social infrastructure would thus quantify the wedge between the private return to productive activities and the social return to such activities (Hall and Jones, 1999). Seeing in practice we do not have a usable quantification of wedges between private and social returns, we need to come up with a proxy or indicator variable to represent social infrastructure. We argue that openness to international activities is an acceptable proxy variable for social infrastructure. Policies and practices concerned with international activities such as foreign trade and FDI are sensitive and meaningful indexes of social infrastructure (Jiang, 2011). This is to say that in addition to the function of openness as a proxy variable for technology acquisition (as the former facilitates technology spillovers from other countries), openness can also serve as a proxy variable for social infrastructure where the latter is in itself a proxy variable for both technology acquisition and technology creation. However, we do not need to distinguish between the function of openness as a general proxy variable for social infrastructure and that of openness as a factor that facilitates technology spillovers due to freer trade and FDI inflows. This is because later on we will combine the openness variable with the aforementioned $R \& D$ variables into a single, unified macro technology index representing the overall regional level of technology, which takes account of both technology creation and technology acquisition combined.

Owing to data constraints, we opt for the use of the regional trade-to-GDP ratio as a measure of regional openness, which is constructed as the ratio of total value of regional foreign trade (regional exports plus regional imports, converted from USD to RMB yuan) to regional GDP in RMB yuan. According to the China Statistical Yearbook, there are two types of "total values of foreign trade": one is "Total Value of Imports and Exports by Location of China's Foreign Trade Managing Units" and the other is "Imports Value of Commodities by the Places of Their Destination and Exports Value of Commodities by the Places of Their Origin in China". Therefore, we construct two trade-to-GDP ratios based on the two types of "total values of foreign trade" provided by the Yearbook. In the lower section of Table 1, we present the basic descriptive statistics of two versions of the regional openness variables for the year 2012: $X_{1}$ is regional trade-to-GDP ratio calculated based on "Total Value of Imports and Exports by Location of China's Foreign Trade Managing Units" while $X_{2}$ is regional trade-to-GDP ratio calculated based on "Imports Value of Commodities by the Places of Their Destination and Exports Value of Commodities by the Places of Their Origin in China". A quick look at Table 1 reveals that there exists significant disparity in the level of regional openness across the 31 Chinese regions. In the lower section of Table 2, we present the correlation between $X_{1}$ and $X_{1}$, as well as all the pair-wise correlations of each of $X_{1}$ and $X_{1}$ with any of the six " $V$ variables" $\left(V_{1}\right.$ through $\left.V_{6}\right)$, where we see that the values of the 
correlation coefficients are all positive and practically large. This observation, in a sense, implies substitutability between the two groups of variables and thus justifies our merging the two groups into a single, unified technology index, which we do next.

To construct the regional technology index, we normalize the values of all the eight variables so that all the values for one arbitrarily chosen region, Beijing, are unity in the specific year 2012. The normalized values are then averaged across the eight variables to obtain a single value of the technology index for each region in any given year, using weights as follows:

$$
T=\tilde{V}_{1} / 8+\tilde{V}_{2} / 8+\tilde{V}_{3} / 8+\tilde{V}_{4} / 32+\tilde{V}_{5} / 32+\tilde{V}_{6} / 16+\tilde{Z}_{1} / 4+\tilde{Z}_{2} / 4
$$

where $T$ refers to the technology index and the values of the right-hand side variables (i.e. the "tilde variables") are the corresponding normalized values. ${ }^{4}$

Heuristically, we expect that technology and people's standard of living should be positively related. The scatterplot in Figure 1, for example, reveals the positive correlation between our computed regional technology index and regional per capita GDP (the most widely and frequently used measure for the standard of living). The sample points in Figure 1 are the 31 Chinese provincial-level regions (single cross-sectional data for 2012). The horizontal axis depicts the regional technology index and vertical axis depicts regional per capita GDP (in 10 thousand RMB yuan per person). To get down to more detailed discussions, in the subsequent sections we set out exploring the relationships between the regional technology index and various other regional socio-economic indicators in the hope of finding useful clues regarding how technology progress may promote socio-economic development. Our focus is on the mutual linkage between technology and the level of socio-economic development in the Chinese regions.

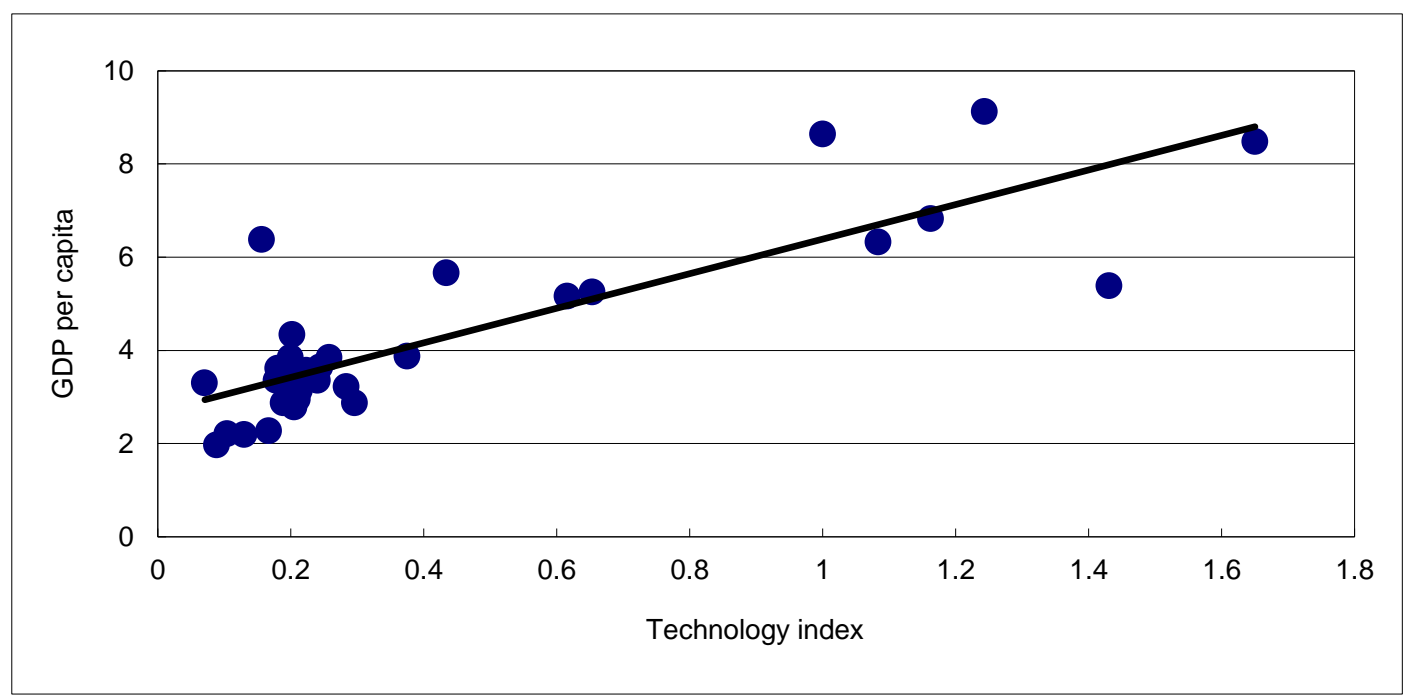

Figure 1. Regional technology index and GDP per capita in 2012

The sample points are 31 Chinese provincial-level regions in the year 2012. The horizontal axis depicts the regional technology index and vertical axis depicts regional per capita GDP (measured in 10 thousand RMB yuan per person).

\section{Technology, Production and Socio-Economic Indicators}

Socio-economic development takes goods production activities as its foundation. Economy-wide production can be captured by an aggregate production function, which can be mathematically represented as the following general form:

$$
Y=A \cdot F(K, H, Z, L)
$$

where $F$ denotes the functional form, $Y$ is aggregate output (value added), $K$ and $H$ are two representative production inputs, namely, physical and capital and human capital, $Z$ is the amount of environmental input, $L$ is the amount of raw-labor input, and $A$ is the so-called total factor productivity, which is a black box capturing anything in the (aggregate) production process that cannot be accounted for by the explicitly included production inputs (in this case, $K$, $H$ and $Z$ ). Assuming the aggregate production function follows constant returns to scale, it can then be rewritten in its intensive form in per capita terms as:

\footnotetext{
${ }^{4}$ Values of the technology index can be computed in the same way for any year other than 2012 , so that a panel data set can be obtained.
} 


$$
y=A \cdot f(k, h, z)
$$

where $f$ denotes the functional relationship in the intensive form. The lowercase letters $y, k, h$ and $z$ denote per capita levels of output, physical and human capital, and environmental input, respectively. According to neoclassical growth models, on a balanced growth path over time, the levels of $k, h$ and $z$, now specifically denoted with an asterisk, $k^{*}, h^{*}$ and $z^{*}$, are in themselves dependent on the contemporaneous level of $A$. Therefore, per capita output, denoted $y^{*}$, can be written as a function of $A$ :

$$
y^{*}=A \cdot f\left[k *\left(A, \mathbf{w}_{k}\right), h *\left(A, \mathbf{w}_{h}\right), z *\left(A, \mathbf{w}_{z}\right)\right]
$$

where the w's are vectors of other factors influencing the levels of $k^{*}, h^{*}$ and $z^{*}$ (respectively) on the balanced growth path. Equation (4) shows that the (contemporaneous) level of total factor productivity affects per capita output through two different channels: one is a direct effect as $A$ is a direct argument in the aggregate production function while the other is an indirect effect as $A$ is one of the ultimate influencing factors behind the three direct arguments $k, h$ and $z$.

Our analysis in this section is motivated by equation (4). We go one step further to consider what key factors should be contained in the $\mathbf{w}$ vectors. Growth theories tell us that the investment rate (denoted $s$ hereinafter) and the population growth rate (denoted $n$ hereinafter) are two important elements in $\mathbf{w}_{k}$. Labor economists argue that educational attainment (denoted $u$ hereinafter) is an important determinant of human capital intensity (per capita human capital) $h$, that is, $u$ should be an important element contained in $\mathbf{w}_{h}$. Environmental economics tells us that per capita pollution emission (denoted $p$ hereinafter) is a primary factor influencing the per capita level of environmental input used for production, that is, $p$ is a key element in the vector $\mathbf{w}_{\mathrm{z}}$. In addition, the industry mix (the proportions of different industries in the aggregate economy in terms of either the labor shares or output shares) can be an indispensable element in any of $\mathbf{w}_{k}, \mathbf{w}_{h}$ and $\mathbf{w}_{z}$. These selected (and many other) elements of the $\mathbf{w}$ vectors are highly likely to be related to $A$ in a way or another. If we equate total factor productivity to technology and take our constructed technology index (see the preceding section) as a practical measure of total factor productivity $A$, we are now interested in finding out how technology (as represented by our technology index) is related to the various socio-economic indicators: the investment rate $s$, the population growth rate $n$, the (average) educational attainment $u$ (for which we will use the share of the people who have finished a three-year college or above in the population aged six or above as a practical measure), the per capita level of pollution emission $p$ (for which we will use the per capita level of sulphur dioxide emission in waste gas as a feasible measure), as well as the industry mix (for which we will use the output share of agriculture, i.e. the value of agricultural output divided by the total value of overall aggregate output, hereinafter denoted $m$, as a practical measure).

For the 31 Chinese regions in the year 2012, we collect data on the above-mentioned socio-economic indicators. The regional investment rate $\mathrm{s}$ is calculated by dividing regional gross capital formation by regional output (measured by gross regional product (GRP) by the expenditure approach), where gross capital formation refers to the fixed assets acquired less disposals and the net value of inventory, including gross fixed capital formation and changes in inventories, and gross regional product by the expenditure approach refers to the method of measuring the final results of production activities of the region during a given period (usually one year) from the perspective of final uses, which includes final consumption expenditure, gross capital formation and net export of goods and services. ${ }^{5}$ The regional population growth rate $n$ is calculated as the regional natural growth rate of population, which refers to the ratio of the natural increase in population (the number of births minus the number of deaths) in a given period (usually one year) to the average population (or mid-period population) of the same period. The regional average educational attainment $u$, as was mentioned already, is measured by the ratio of the number of the regional residents who have finished a three-year college or above to the regional population aged six or above. The regional pollution emission intensity (i.e. per capita pollution emission) $p$, as mentioned earlier, is measured by the per capita level of regional sulphur dioxide emission in waste gas (in tons per person). The regional industry mix, as mentioned earlier too, is measured by the share of regional agricultural output in total regional output (where regional output is measured by GRP).

The descriptive statistics of the variables are summarized in Table 3. To see the interrelationships among the indicators, we further present the pair-wise correlations between the variables in Table 4. The results show that a higher level of technology tends to be associated with a lower investment rate, a lower population growth rate, a higher level of human capital intensity (or average educational attainment), a lower level of per capita pollution emission, and a lower share of the agricultural sector in GRP (which indicates a higher degree of industrialization), respectively. The signs of the correlations are in general consistent with the predictions economic theory could offer regarding the interrelations between these indicators. A thorough discussion on this point is beyond the scope of the current analysis because it

\footnotetext{
5 According to the China Statistical Yearbook, gross fixed capital formation refers to the value of acquisitions less those disposals of fixed assets during a given period (usually one year). Gross fixed capital formation can be categorized into total tangible fixed capital formation and total intangible fixed capital formation.
} 
would take us too far afield into some involved areas of macroeconomics. However, one thing we can see from the results in that a higher level of technology is always associated with socio-economically desirable outcomes on the other variables. For example, a lower investment rate is a socio-economically desirable outcome of physical investment in the sense that advancements in technologies (and management skills) can be regarded as a substitute for physical capital accumulation in the production process so that a higher level of technology can afford a lower rate of physical investment, leading to a higher consumption rate that is socially desirable. Similarly, a higher level of technology is associated with a lower rate of population growth, which is also a desirable goal in the context of China's growth as China is currently so much overpopulated. In addition, a higher level of technology is associated with a higher level of human capital intensity (or educational attainment), a lower level of per capita pollution emission, and a higher level of industrialization, which are all desirable goals of the society.

Table 3. The means, standard deviations, and minimal and maximal values of the variables in 2012

\begin{tabular}{cccccc}
\hline Variable & Obs & Mean & Std. Dev. & Min & Max \\
\hline$T$ & 31 & 0.441647 & 0.438888 & 0.070686 & 1.650108 \\
$s$ & 31 & 0.64115 & 0.160914 & 0.380286 & 1.01087 \\
$n$ & 31 & 0.005452 & 0.002684 & -0.00039 & 0.01084 \\
$u$ & 31 & 0.114405 & 0.064935 & 0.042453 & 0.373503 \\
$p$ & 31 & 0.018299 & 0.013838 & 0.00136 & 0.062831 \\
$m$ & 31 & 0.105077 & 0.051974 & 0.006333 & 0.249179 \\
\hline
\end{tabular}

The variables in this table are defined the same as in the text.

Table 4. Pair-wise correlations between the variables in 2012

\begin{tabular}{ccccccc}
\hline & $T$ & $s$ & $n$ & $u$ & $p$ & $m$ \\
\hline$T$ & 1 & & & & & \\
\hline$s$ & -0.5657 & 1 & & & & \\
$n$ & -0.2392 & 0.3457 & 1 & & & \\
$u$ & 0.6174 & -0.3845 & -0.3388 & 1 & & \\
$p$ & -0.3301 & 0.4192 & 0.0578 & -0.1096 & 1 & 1 \\
$m$ & -0.7073 & 0.3517 & 0.3623 & -0.6049 & -0.0637 & \\
\hline
\end{tabular}

All the variables in this table are defined the same as in Table 3.

However, the correlations shown in Table 4 do not provide us with adequate information to imply any unidirectional causal relationship within each pair. The causality is likely to be bi-directional, running both ways from one variable to the other in each pair. For example, technological improvement may be a cause that contributes to the realization of desirable outcomes concerning the other variables. Or conversely, desirable outcomes of the other variables can be causes that, separately or collectively, contribute to advances in technology.

Having done the correlation exercise, we now turn to a regression analysis. We regress regional per capita output on the six variables in Table 3. The results of the regressions are summarized in Table 5, where we opt to include four variant versions of essentially the same regression, of which the last one has the best fit. All of the estimated partial effects have the expected signs, but some of them are statistically insignificant. In all of the four regressions, the estimated partial effect of technology on per capita output is statistically significant and economically large. We should note that, based on equation (4) earlier, this partial effect of technology, by construction, captures only the direct effect of technology on per capita output while the indirect effects of technology via the other variables are absorbed into the partial effects of the other explanatory variables in the regression specification. Nevertheless, these results undoubtedly suggest that the level of technology plays a crucial role in determining labor productivity (per capita output) in the production process (at the macro level). 
Table 5. Results of the regression analysis

\begin{tabular}{|c|c|c|c|c|c|c|c|}
\hline \multicolumn{8}{|c|}{ Dependent variable: $\ln y$} \\
\hline Variable & $\begin{array}{c}\text { Coef. } \\
\text { (Std. Err.) }\end{array}$ & Variable & $\begin{array}{c}\text { Coef. } \\
\text { (Std. Err.) }\end{array}$ & Variable & $\begin{array}{c}\text { Coef. } \\
\text { (Std. Err.) }\end{array}$ & Variable & $\begin{array}{c}\text { Coef. } \\
\text { (Std. Err.) }\end{array}$ \\
\hline$T$ & $\begin{array}{l}0.626 * \\
(0.141)\end{array}$ & $T$ & $\begin{array}{l}0.601 * \\
(0.143)\end{array}$ & $T$ & $\begin{array}{l}0.593 * \\
(0.159)\end{array}$ & $\ln T$ & $\begin{array}{l}0.345 * \\
(0.060)\end{array}$ \\
\hline$s$ & $\begin{array}{c}0.328 \\
(0.275)\end{array}$ & $s$ & $\begin{array}{c}0.443 \\
(0.271)\end{array}$ & $\ln s$ & $\begin{array}{c}0.274 \\
(0.184)\end{array}$ & $\ln s$ & $\begin{array}{l}0.366 * \\
(0.151)\end{array}$ \\
\hline$n$ & $\begin{array}{c}-39.527^{*} \\
(14.181)\end{array}$ & $n$ & $\begin{array}{c}-34.865^{*} \\
(14.775)\end{array}$ & $\ln n$ & $\begin{array}{c}-0.105 \\
(0.055)\end{array}$ & $\ln n$ & $\begin{array}{c}-0.093 * \\
(0.044)\end{array}$ \\
\hline$u$ & $\begin{array}{l}1.929 * \\
(0.697)\end{array}$ & $u$ & $\begin{array}{l}2.036 * \\
(0.716)\end{array}$ & $\ln u$ & $\begin{array}{l}0.337 * \\
(0.138)\end{array}$ & $\ln u$ & $\begin{array}{l}0.239 * \\
(0.114)\end{array}$ \\
\hline$p$ & $\begin{array}{c}5.250 \\
(2.986)\end{array}$ & $\ln p$ & $\begin{array}{c}0.070 \\
(0.052)\end{array}$ & $\ln p$ & $\begin{array}{c}0.051 \\
(0.050)\end{array}$ & $\ln p$ & $\begin{array}{c}0.084 \\
(0.042)\end{array}$ \\
\hline$m$ & $\begin{array}{l}-0.229 \\
(1.091)\end{array}$ & $m$ & $\begin{array}{c}-0.518 \\
(1.084)\end{array}$ & $\ln m$ & $\begin{array}{c}-0.034 \\
(0.086)\end{array}$ & $\ln m$ & $\begin{array}{l}-0.092 \\
(0.060)\end{array}$ \\
\hline _cons & $\begin{array}{c}0.812 \\
(0.273) \\
\end{array}$ & _cons & $\begin{array}{c}1.134 \\
(0.304) \\
\end{array}$ & _cons & $\begin{array}{c}1.578 \\
(0.602) \\
\end{array}$ & _cons & $\begin{array}{c}2.145 \\
(0.512) \\
\end{array}$ \\
\hline obs & 31 & & 31 & & 30 & & 30 \\
\hline $\mathrm{R}^{2}$ & 0.844 & & 0.837 & & 0.832 & & 0.889 \\
\hline
\end{tabular}

The dependent variable is log regional per capita output measured by log per capita GRP. Four versions of essentially the same regression are included in this table. Owing to one negative value of $n$ in the sample, the last two regressions lose one sample point. An asterisk * indicates statistical significance at the $5 \%$ level.

\section{Regression Exercise with Panel Data}

While the results above, which we have obtained based on the dataset of the year 2012, appear rather plausible, it surely would have made much more sense had data of additional years been added. Therefore, in this section, data of the years 2009 and 2011 are included to form a panel data structure (data of 2010 are not available as a different statistical categorization was used for 2010), which allows for the possibility of an improvement in the regression technique that can be applied.

Before we start our regression analysis, a few assumptions ought to be examined. The results of the examinations can be illustrated by the following four plots. ${ }^{6}$

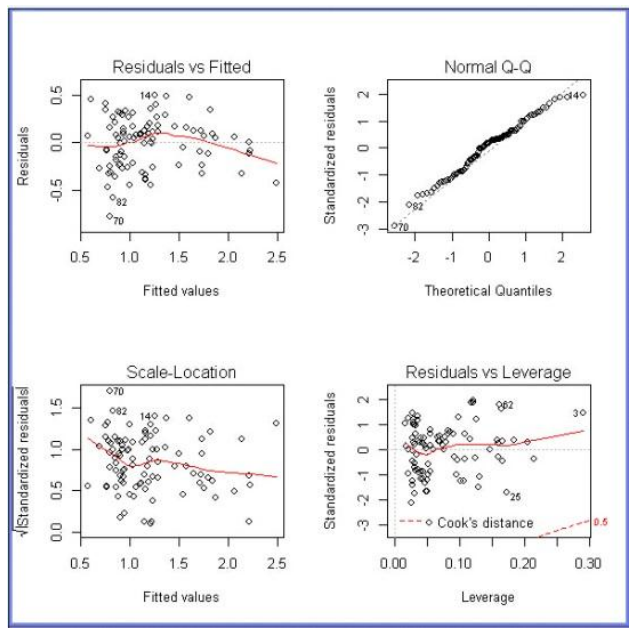

Figure 2a. Independent variables take the original forms

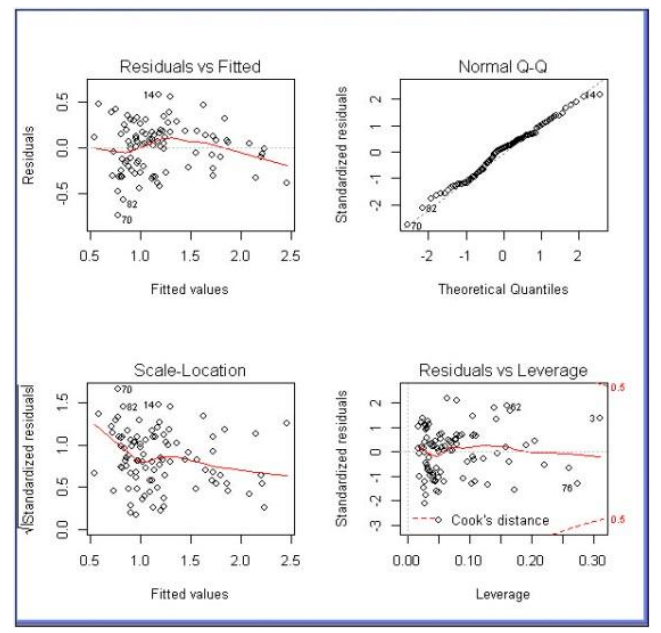

Figure 2b. $\mathrm{p}$ takes the form of natural logarithm

\footnotetext{
${ }^{6}$ All results hereafter are obtained by using R 3.1.1. For a better understanding of these plots, we should note two major assumptions. (1) Normality: with the independent variables given, the dependent variable should fit into a normal distribution, which in turn, indicates that the error terms follow a normal distribution as well. This could certainly be supported by a normal distribution presented by the residuals. With the values under the assumed normal distribution given, the Normal-QQ graph (the upper right) depicts the probability of standardized residuals. If the normality assumption is met, dots on the plot should fall upon the 45-degree line, otherwise a violation of the assumption is signaled. (2) Homoskedasticity: in the Scale-Location Graph (the lower left), dots around the horizontal line should follow a stochastic process if the homoskedasticity assumption is met.
} 


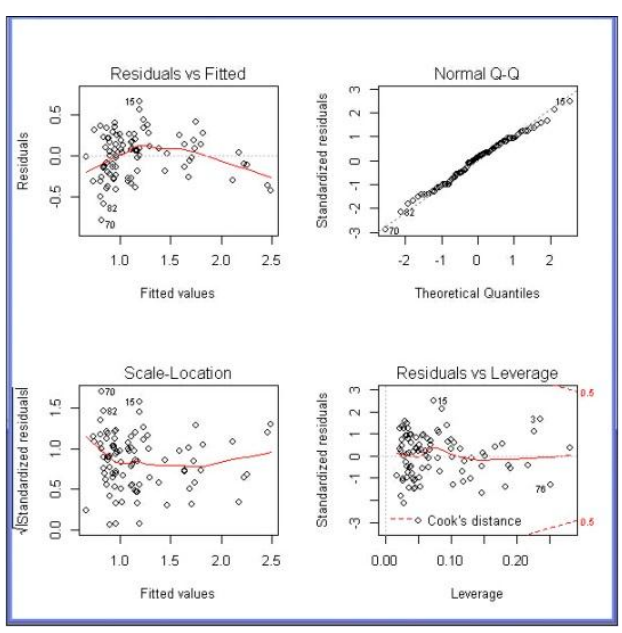

Figure 2c. Independent variables except $\mathrm{T}$ in the form of natural log

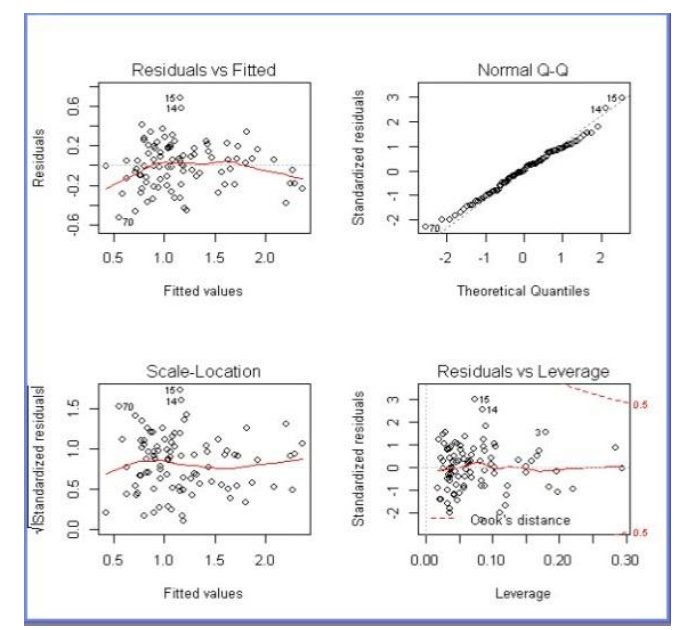

Figure 2d. Independent variables in the form of natural $\log$

As is clearly illustrated by the 4 plots above, it may well be verified that the assumptions of normality and homoskedasticity are by no means violated under whichever type of variable setting. Hence the estimators obtained from the following panel data regressions may stand clear of the suspicion of being biased or inconsistent.

Three commonly used methods are employed, one after another to take advantage of the panel structure. The three methods are the pooled OLS, the fixed-effects, and the random-effects estimators. Surely the necessity of adopting a certain method needs to be checked before its being put into use. In the first place, it is of interest to check whether the fixed effects are really needed. This is done by comparing the fixed-effects and the pooled OLS fits, which yields the following results. In addition, we conduct an analysis using R to strip off the fixed effect of each of the 31 provinces and hereby display its estimate together with its $t$-value and $\mathrm{p}$-value. In line with the way we dealt with the independent variables above, the results are displayed under each of the four variable type settings:

Type 1: All independent variables in the original form

$\mathrm{F}$ test for effects

$$
\begin{gathered}
\text { data: } \log (\mathrm{y}) \sim \mathrm{T}+\mathrm{s}+\mathrm{n}+\mathrm{u}+\mathrm{p}+\mathrm{m} \\
\mathrm{F}=6.0243, \mathrm{df} 1=30, \mathrm{df} 2=56, \mathrm{p} \text {-value }=4.182 \mathrm{e}-09 \\
\text { alternative hypothesis: significant effects }
\end{gathered}
$$

\#fixed effect stripping 


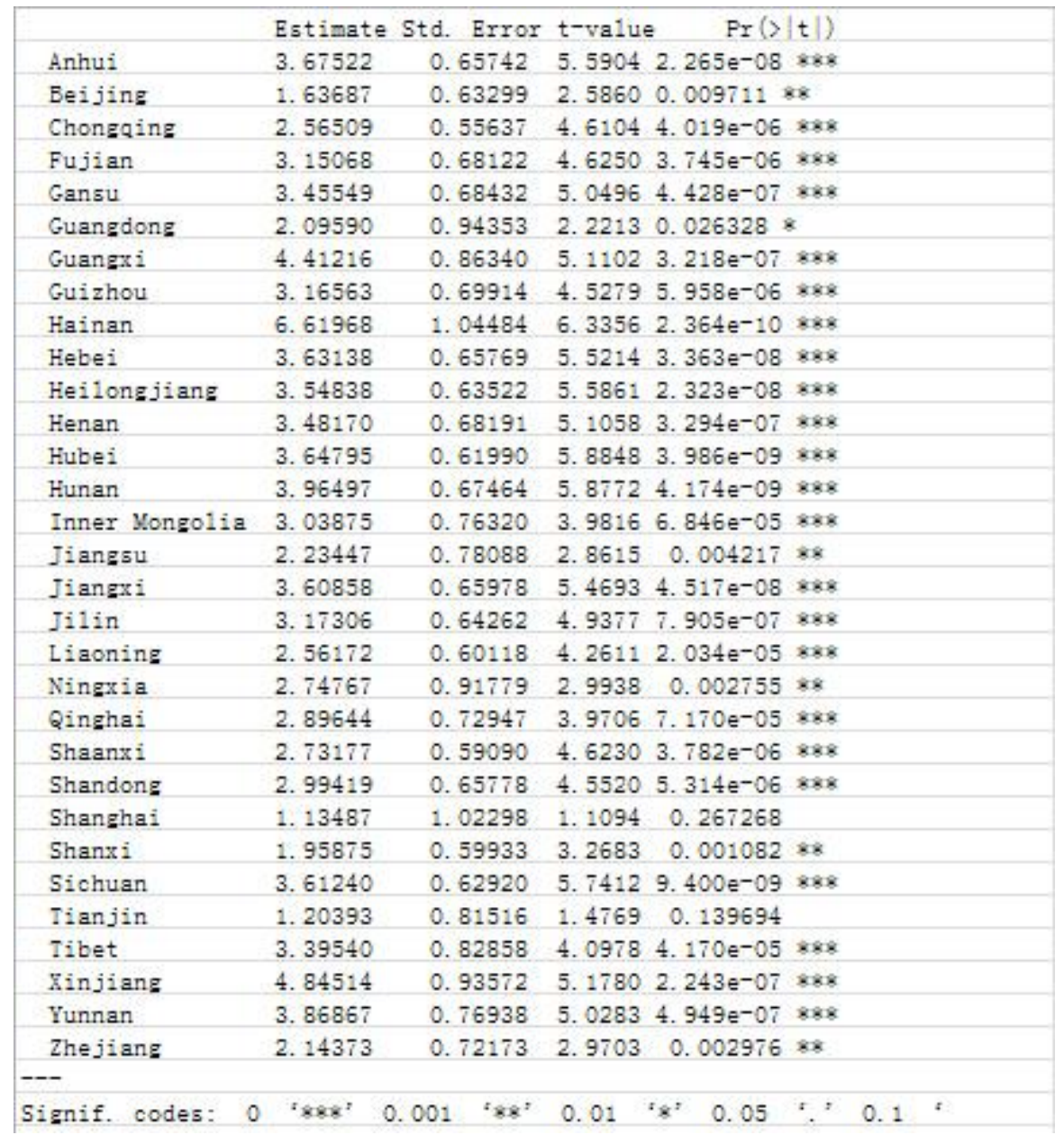

Type 2: $p$ takes the form of natural logarithm

$F$ test for effects

data: $\log (\mathrm{y}) \sim \mathrm{T}+\mathrm{s}+\mathrm{n}+\mathrm{u}+\log (\mathrm{p})+\mathrm{m}$

$\mathrm{F}=6.7909, \mathrm{df} 1=30, \mathrm{df} 2=56, \mathrm{p}$-value $=4.469 \mathrm{e}-10$

alternative hypothesis: significant effects

\#fixed effect stripping 


\begin{tabular}{|c|c|c|c|c|c|}
\hline & Estimate & td. Error & $t$-value & $=\operatorname{Pr}(\rangle|t|)$ & \\
\hline Anhui & 2. 383869 & 0.879843 & 2. 7094 & 0.006740 & 88 \\
\hline Beijing & 0.092559 & 0.951693 & 0.0973 & 0.922522 & \\
\hline Chongqing & 1. 479653 & 0.732545 & 2.0199 & 0.043396 & 8 \\
\hline Fujian & 1. 877012 & 0.889993 & 2. 1090 & 0.034943 & 8 \\
\hline Gansu & 2. 443478 & 0.802534 & 3.0447 & 0.002329 & 88 \\
\hline Guangdong & 0.760175 & 1. 105904 & 0.6874 & 0.491844 & \\
\hline Guangxi & 3. 223856 & 1. 001532 & 3. 2189 & 0.001287 & 88 \\
\hline Guizhou & 2. 283485 & 0.759396 & 3.0070 & 0.002639 & 88 \\
\hline Hainan & 5.093866 & 1. 237938 & 4. 1148 & 3. $875 e-05$ & 8888 \\
\hline Hebei & 2. 563840 & 0.802127 & 3. 1963 & 0.001392 & 88 \\
\hline Heilongjiang & 2. 281479 & 0.856509 & 2. 6637 & 0.007729 & 88 \\
\hline Henan & 2. 271121 & 0.869981 & 2. 6105 & 0.009040 & 88 \\
\hline Hubei & 2. 380357 & 0.846142 & 2. 8132 & 0.004905 & 88 \\
\hline Hunan & 2. 732710 & 0.872278 & 3. 1328 & 0.001731 & 88 \\
\hline Inner Yongolia & 2. 282570 & 0.699261 & 3. 2643 & 0.001098 & 88 \\
\hline Jiangsu & 0.941674 & 0.968524 & 0.9723 & 0.330913 & \\
\hline Jiangx $i$ & 2. 450354 & 0.836389 & 2. 9297 & 0.003393 & 88 \\
\hline $\mathrm{Jilin}$ & 1. 880164 & 0.870222 & 2. 1606 & 0.030730 & $*$ \\
\hline Liaoning & 1. 441172 & 0.776588 & 1. 8558 & 0.063486 & . \\
\hline Ningxia & 2. 084122 & 0.799823 & 2. 6057 & 0.009168 & 88 \\
\hline Qinghai & 1. 921914 & 0.818327 & 2. 3486 & 0.018845 & 8 \\
\hline Shaanxi & 1. 653205 & 0.754033 & 2. 1925 & 0.028345 & $*$ \\
\hline Shandong & 1. 869934 & 0.820857 & 2. 2780 & 0.022725 & 8 \\
\hline Shanghai & -0.192190 & 1. 166694 & -0.1647 & 0.869156 & \\
\hline Shanxi & 1. 069988 & 0.661547 & 1. 6174 & 0. 105791 & \\
\hline Sichuan & 2. 347985 & 0.851558 & 2. 7573 & 0.005828 & 88 \\
\hline Tianjin & -0.072100 & 0.987322 & -0.0730 & 0.941785 & \\
\hline Tibet & 1. 469474 & 1. 209703 & 1. 2147 & 0.224465 & \\
\hline Xinjiang & 4.041836 & 0.938754 & 4. 3055 & 1. $666 \mathrm{e}-05$ & 888 \\
\hline Yunnan & 2. 666402 & 0.932731 & 2. 8587 & 0.004254 & 88 \\
\hline Zhejiang & 0.872871 & 0.917719 & 0.9511 & 0.341538 & \\
\hline \multicolumn{6}{|l|}{--} \\
\hline ignif. codes: & $0{ }^{\prime} 80888^{\prime}$ & $01{ }^{\prime} 888^{\prime}$ & 0.01 & $8^{2} \quad 0.05$ & $\because 0.1=$ \\
\hline
\end{tabular}

Type 3: All independent variables with $\mathrm{T}$ as an exception in the form of natural logarithm

$F$ test for effects

data: $\log (\mathrm{y}) \sim \mathrm{T}+\log (\mathrm{s})+\log (\mathrm{n})+\log (\mathrm{u})+\log (\mathrm{p})+\log (\mathrm{m})$ $\mathrm{F}=8.635$, df $1=30$, df $2=54, \mathrm{p}$-value $=6.857 \mathrm{e}-12$

alternative hypothesis: significant effects

\#fixed effect stripping 


\begin{tabular}{|c|c|c|c|}
\hline & Estimate & Std. Error t-value $\operatorname{Pr}(\rangle|t|)$ & \\
\hline Anhui & -5.04092 & $0.93795-5.3744 \quad 7.685 e-08$ & 808 \\
\hline Beijing & -11.02261 & 1. $60344-6.8744 \quad 6.226 e^{-12}$ & 808 \\
\hline Chongaing & -6.08585 & $0.99467-6.11849 .450 \mathrm{e}-10$ & 8088 \\
\hline Fujian & -5.75244 & $1.00349-5.7324 \quad 9.901 \mathrm{e}-09$ & 888 \\
\hline Gansu & -5.19978 & $0.87589-5.9366 \quad 2.910 \mathrm{e}-09$ & 808 \\
\hline Guangdong & -7.40274 & 1. $25675-5.8904 \quad 3.852 \mathrm{e}-09$ & 808 \\
\hline Guangxi & -4.84620 & $0.85734-5.6526 \quad 1.580 \mathrm{e}-08$ & 8088 \\
\hline Guizhou & -5.41064 & $0.86530-6.2529 \quad 4.030 \mathrm{e}-10$ & 888 \\
\hline Hainan & -3.56242 & $0.91918-3.8757 \quad 0.0001063$ & 888 \\
\hline Hebei & -5.02932 & $0.90561-5.5535 \quad 2.800 \mathrm{e}-08$ & 808 \\
\hline Heilongjiang & -5.15491 & $0.99519-5.1798 \quad 2.221 \mathrm{e}-07$ & 8088 \\
\hline Henan & -5.31578 & $0.91995-5.77847 .543 e-09$ & 888 \\
\hline Hubei & -4.98202 & $0.95042-5.2419 \quad 1.589 \mathrm{e}-07$ & s8:8 \\
\hline Hunan & -4.78642 & $0.91466-5.2330 \quad 1.668 \mathrm{e}-07$ & 2088 \\
\hline Inner Yongolia & -5.54265 & $0.93618-5.9205 \quad 3.210 e-09$ & 888 \\
\hline Jiangsu & -6.90218 & 1. $16560-5.9215$ 3. $189 \mathrm{e}-09$ & 888 \\
\hline Jiangx $i$ & -5.10005 & $0.91718-5.5606 \quad 2.689 e-08$ & 808 \\
\hline Jilin & -5.70479 & 1. $04554-5.4563 \quad 4.861 \mathrm{e}-08$ & 808 \\
\hline Liaoning & -6.33598 & 1. $06645-5.9412 \quad 2.830 \mathrm{e}-09$ & 8088 \\
\hline Ningxia & -6.17679 & $0.89079-6.9341 \quad 4.089 e-12$ & 888 \\
\hline Qinghai & -6.01970 & $0.92523-6.5062$ 7. $710 e^{-11}$ & 888 \\
\hline Shaanxi & -5.93079 & $0.96639-6.1371$ 8. $406 e^{-10}$ & 808 \\
\hline Shandong & -5.77603 & $0.99026-5.8328 \quad 5.449 e-09$ & 808 \\
\hline Shanghai & -12.25421 & 1. $73091-7.0796 \quad 1.445 e-12$ & 888 \\
\hline Shanxi & -7.02546 & 1. $03439-6.7919$ 1. $107 e^{-11}$ & 888 \\
\hline Sichuan & -5.00588 & 0. $95278-5.2540 \quad 1.488 \mathrm{e}-07$ & 808 \\
\hline Tianjin & -10.68620 & 1. $44446-7.3981$ 1. $381 \mathrm{e}-13$ & 8088 \\
\hline Tibet & -6.03992 & 1. $10533-5.4644 \quad 4.646 \mathrm{e}-08$ & 888 \\
\hline Xinjiang & -4.32610 & 0. $77891-5.5540$ 2.791e-08 & 888 \\
\hline Yunnan & -5.12408 & $0.88143-5.81346 .123 \mathrm{e}-09$ & 808 \\
\hline Zhejiang & -7.23149 & 1. $18332-6.11129 .889 e-10$ & 808 \\
\hline \multicolumn{4}{|c|}{$=0$} \\
\hline Bignif. codes: 0 & ' 8888 ' & 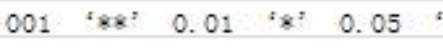 & $\because 0.1=$ \\
\hline
\end{tabular}

Type 4: All independent variables take the form of natural logarithm

$F$ test for effects

data: $\log (\mathrm{y}) \sim \log (\mathrm{T})+\log (\mathrm{s})+\log (\mathrm{n})+\log (\mathrm{u})+\log (\mathrm{p})+\log (\mathrm{m})$

$\mathrm{F}=5.6633, \mathrm{df} 1=30, \mathrm{df} 2=54, \mathrm{p}$-value $=1.844 \mathrm{e}-08$

alternative hypothesis: significant effects

\#fixed effect stripping 


\begin{tabular}{|c|c|c|c|c|c|}
\hline & Estimate & Std. Error & t-value & $\operatorname{Pr}(>\mid t$ & \\
\hline Anhui & -5.44932 & 1. 04850 & -5.1973 & 2. $023 e-07$ & 8080 \\
\hline Beijing & -11.38590 & 1. 75777 & -6.4775 & 9. $328 e-11$ & 888 \\
\hline Chongqing & -6.62168 & 1. 13530 & -5.8325 & 5. $459 e^{-09}$ & 888 \\
\hline Fujian & -5.84620 & 1. 07281 & -5.4494 & $5.053 e-08$ & 888 \\
\hline Gansu & -5.88388 & 1. 05798 & -5.5614 & 2. $676 e^{-08}$ & 8088 \\
\hline Guangdong & -6.79268 & 1. 20169 & -5.6526 & 1. $580 \mathrm{e}-08$ & 888 \\
\hline Guangxi & -5.37494 & 0.99412 & -5.4067 & 6. $419 e^{-08}$ & 888 \\
\hline Guizhou & -6.23123 & 1. 09608 & -5.6850 & 1. $308 e-08$ & 888 \\
\hline Hainan & -3.70898 & 0.97398 & -3.8080 & 0.0001401 & 8088 \\
\hline Hebei & -5.54982 & 1. 04415 & -5.3151 & $1.066 e^{-07}$ & 8888 \\
\hline Heilongjiang & -5.63902 & 1. 11223 & -5.0700 & 3. $978 e^{-07}$ & 888 \\
\hline Henan & -5.90377 & 1. 06668 & -5.5347 & 3. $117 e^{-08}$ & 288 \\
\hline Hubei & -5.42460 & 1.06617 & -5.0879 & 3. $620 \mathrm{e}-0 \mathrm{t}$ & 8088 \\
\hline Hunan & -5.28015 & 1.04277 & -5.0636 & 4. $114 \mathrm{e}^{-0} \mathrm{z}$ & 888 \\
\hline Inner Yongolia & -6.41688 & 1. 15815 & -5.5406 & 3. $014 e^{-08}$ & $\$ 888$ \\
\hline Jiangsu & -6.58161 & 1. 17167 & -5.6173 & 1. $940 \mathrm{e}-08$ & 808 \\
\hline Jiangxi & -5.66552 & 1. 06371 & -5.3262 & 1. $003 e^{-07}$ & 8088 \\
\hline Jilin & -6.35458 & 1. 18931 & -5.3431 & 9. $138 \mathrm{e}-08$ & 888 \\
\hline Liaoning & -6.65884 & 1. 16884 & -5.6970 & 1. $219 e-08$ & 888 \\
\hline Ningxia & -7.00444 & 1. 10858 & -6.3184 & 2. $643 e^{-10}$ & 808 \\
\hline Qinghai & -7.01832 & 1. 19709 & -5.8628 & 4. $551 e^{-09}$ & 888 \\
\hline Shaanxi & -6.63013 & 1. 13833 & -5.8244 & 5. $731 e-09$ & 888 \\
\hline Shandong & -5.91694 & 1. 07013 & -5.5292 & 3. $217 e^{-08}$ & 888 \\
\hline Shanghai & -12.00500 & 1. 80383 & -6.6553 & 2. $828 e^{-11}$ & 888 \\
\hline Shanxi & -7.91463 & 1. 25117 & -6.3258 & 2. $520 \mathrm{e}-10$ & 8088 \\
\hline Sichuan & -5.52647 & 1. 08183 & -5.1084 & 3. $248 \mathrm{e}-07$ & 8888 \\
\hline Tianjin & -10.77205 & 1. 56104 & -6.9006 & 5. $179 e-12$ & 888 \\
\hline Tibet & -6.74384 & 1. 26227 & -5.3426 & 9. $160 \mathrm{e}-08$ & 888 \\
\hline Xinjiang & -4.77029 & 0.91042 & -5.2397 & 1. $609 e-07$ & 8088 \\
\hline Yunnan & -5.83288 & 1. 06706 & -5.4663 & 4. $595 e-08$ & 888 \\
\hline Zhejiang & -7.06715 & 1. 22355 & -5.7759 & 7. $653 e^{-09}$ & 888 \\
\hline \multicolumn{6}{|c|}{ 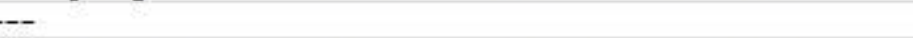 } \\
\hline Enif. cod & 0 '8888' & 01 ' $^{\circ}$ & 0.01 & $8^{\prime} \quad 0.05$ & $\because "$ \\
\hline
\end{tabular}

Given the results displayed, we may arrive at a conclusion that there exists a substantial inter-provincial variation and taking the assumed fixed effects into consideration is not entirely meaningless.

Having no further concern with the comparison between the pooling method and the fixed-effects method, we naturally gravitate to another comparison between the latter and the random-effects method. As was the case with the fixed-effects regression, it is of interest to check whether the random effects are really needed. We have this settled by implementing a comparison between the fixed-effects and random-effects methods in a way quite similar to that of the prior case. The results of the tests are listed below:

Type 1: All independent variables in original form

Hausman Test

data: $\log (\mathrm{y}) \sim \mathrm{T}+\mathrm{s}+\mathrm{n}+\mathrm{u}+\mathrm{p}+\mathrm{m}$

chisq $=57.5702, \mathrm{df}=6, \mathrm{p}$-value $=1.4 \mathrm{e}-10$

alternative hypothesis: one model is inconsistent

Type 2: $\mathrm{p}$ takes the form of natural logarithm

Hausman Test

data: $\log (\mathrm{y}) \sim \mathrm{T}+\mathrm{s}+\mathrm{n}+\mathrm{u}+\log (\mathrm{p})+\mathrm{m}$

chisq $=63.8605, \mathrm{df}=6, \mathrm{p}$-value $=7.369 \mathrm{e}-12$

alternative hypothesis: one model is inconsistent

Type 3: All independent variables with $\mathrm{T}$ as an exception in the form of natural logarithm

\section{Hausman Test}

data: $\log (\mathrm{y}) \sim \mathrm{T}+\log (\mathrm{s})+\log (\mathrm{n})+\log (\mathrm{u})+\log (\mathrm{p})+\log (\mathrm{m})$

chisq $=93.9082, \mathrm{df}=6, \mathrm{p}$-value $<2.2 \mathrm{e}-16$ 
alternative hypothesis: one model is inconsistent

Type 4: All independent variables take the form of natural logarithm

Hausman Test

$$
\begin{gathered}
\text { data: } \log (\mathrm{y}) \sim \log (\mathrm{T})+\log (\mathrm{s})+\log (\mathrm{n})+\log (\mathrm{u})+\log (\mathrm{p})+\log (\mathrm{m}) \\
\text { chisq }=71.1046, \mathrm{df}=6, \mathrm{p} \text {-value }=2.426 \mathrm{e}-13 \\
\text { alternative hypothesis: one model is inconsistent }
\end{gathered}
$$

As is widely accepted that the random-effects method is more efficient than the fixed-effects method when the assumption of exogeneity of the individual effects is strictly met. It is therefore of great importance to test for endogeneity, whose existence definitely portends a case of invalidity of the estimators. The results given by the Hausman Test (which is considered a standard approach to detecting the problem mentioned) have convinced us that endogeneity is not likely to be a problem here, which means the employment of the random-effects method is well justified.

We now present in Table 6 the results of the random-effects method, which we have shown to be more efficient than the other two methods.

\begin{tabular}{|c|c|c|c|c|c|c|c|}
\hline Variable & $\begin{array}{c}\text { Coef. } \\
\text { (Std. Err.) }\end{array}$ & Variable & $\begin{array}{c}\text { Coef. } \\
\text { (Std. Err.) }\end{array}$ & Variable & $\begin{array}{c}\text { Coef. } \\
\text { (Std. Err.) }\end{array}$ & Variable & $\begin{array}{c}\text { Coef. } \\
\text { (Std. Err.) }\end{array}$ \\
\hline$T$ & $\begin{array}{c}0.662 * * * \\
(0.172)\end{array}$ & $T$ & $\begin{array}{c}0.615^{* * *} \\
(0.176)\end{array}$ & $T$ & $\begin{array}{c}0.676^{* *} \\
(0.159)\end{array}$ & $\ln T$ & $\begin{array}{c}0.396 * * * \\
(0.076)\end{array}$ \\
\hline$s$ & $\begin{array}{l}0.847^{*} \\
(0.335)\end{array}$ & $s$ & $\begin{array}{c}0.899 * * \\
(0.336)\end{array}$ & $\ln s$ & $\begin{array}{c}0.735^{* *} \\
(0.237)\end{array}$ & $\ln s$ & $\begin{array}{c}0.725^{* * *} \\
(0.201)\end{array}$ \\
\hline$n$ & $\begin{array}{c}-42.861^{*} \\
(18.360)\end{array}$ & $n$ & $\begin{array}{c}-44.230^{*} \\
(19.271)\end{array}$ & $\ln n$ & $\begin{array}{l}-0.147 \sim \\
(0.076)\end{array}$ & $\ln n$ & $\begin{array}{l}-0.101 \\
(0.064)\end{array}$ \\
\hline$u$ & $\begin{array}{c}0.116 \\
(0.392)\end{array}$ & $u$ & $\begin{array}{c}0.093 \\
(0.387)\end{array}$ & $\ln u$ & $\begin{array}{l}-0.025 \\
(0.017)\end{array}$ & $\ln u$ & $\begin{array}{c}-0.031 \sim \\
(0.114)\end{array}$ \\
\hline$p$ & $\begin{array}{c}0.568 \\
(3.782)\end{array}$ & $\ln p$ & $\begin{array}{l}-0.032 \\
(0.063)\end{array}$ & $\ln p$ & $\begin{array}{c}0.003 \\
(0.066)\end{array}$ & $\ln p$ & $\begin{array}{c}0.012 \\
(0.053)\end{array}$ \\
\hline$m$ & $\begin{array}{l}-3.072 * \\
(1.328)\end{array}$ & $m$ & $\begin{array}{c}-3.570 * * \\
(1.335)\end{array}$ & $\ln m$ & $\begin{array}{l}-0.258^{*} \\
(0.110)\end{array}$ & $\ln m$ & $\begin{array}{c}-0.236^{* *} \\
(0.072)\end{array}$ \\
\hline _cons & $\begin{array}{c}0.927 * * \\
(0.325) \\
\end{array}$ & _cons & $\begin{array}{l}0.851^{*} \\
(0.369)\end{array}$ & _cons & $\begin{array}{l}-0.230 \\
(0.552) \\
\end{array}$ & _cons & $\begin{array}{l}0.873 \sim \\
(0.524)\end{array}$ \\
\hline obs & 93 & & 93 & & 93 & & 93 \\
\hline $\mathrm{R}^{2}$ & 0.547 & & 0.493 & & 0.497 & & 0.610 \\
\hline
\end{tabular}

Table 6. Results of extended regression analysis: the random-effects method

Dependent variable: $\ln y$

Significant Level: ‘***’ $0.001^{\text {'**’ }} 0.01^{\text {'*’ }} 0.05^{\text {' } ~} 0.1^{\prime}$ ' 1

It is not hard for us to spot the key differences between the results in Table 6 and those in Table 5. The primary changes that clearly merit our attention are summarized as the following.

A. The significant level related to $\mathrm{T}$ contracts drastically, from 0.05 to 0.001 on the whole, which denotes an apparent lifting in how much technology weighs in facilitating economic growth.

B. Investment is anything but an irrelevant factor, since its statistical significance experienced an incredible surge, which would sound more sensible in a way that corresponds with most of the growth theories.

C. While population still serves as the primary drag on economic growth, education is no longer of much concern in propelling the economy, as it turns out to be statistically insignificant in the panel data version.

D. The share of the primary industry, whose negative effect was not noteworthy in the single period regression, become rather distinct with the panel data, which we consider reasonable as well, given that technology-driven and capital-intensive businesses have evolved to be the paramount driving forces of the economy.

\section{Concluding Remarks}

The growing role that is being played by technology in shaping socio-economic development is seen in many aspects of a modern society. A society that creates, distributes, and applies technology to generate social wealth gives rise to a networked macro production procedure in which the ability to access and join technology and learning intensive 
relations determines the general performance of the macroeconomy. Technological advancements in society call for the continuous need to create and manage intangible assets that do not depreciate but increase in value over time. This continuous need, in turn, calls for necessary means to generate, distribute, and utilizes technology in ways that increase value to business activities and open new opportunities for enterprises. To date, socio-economic development in China is still based much more heavily on the advantages of low cost labor than on the utilization of advanced technology. To China, one major challenge is how to make full use of technology developed both abroad and domestically. Development in an open, unified, technology-intensive global economy generates continuous pressures on the increasing regional and sectoral disparities within China.

This study focuses on a discussion of the interrelationships between technology, production and various socio-economic variables in the context of China's regional macroeconomy. Our discussion is based on a statistical analysis. After designing a macro-level measure for technology, we move on to explore how this macro-level technology is interrelated to production, output, and various macro-level socio-economic variables. Through our statistical analysis, we find that a higher level of technology is always associated with socio-economically desirable outcomes on the various macro-level indicators. The causality may run bi-directionally: technological improvement may be a cause that contributes to the realization of desirable outcomes concerning the various macro-level indicators, or conversely, desirable outcomes of the macro-level indicators can be causes that, separately or collectively, contribute to advancements in technology. Finally, our regression analysis shows that even after the partial effects of all the other macro-level variables are netted out, that is, even when the indirect effects of technology are not considered, the remaining direct effect of technology is still shown to play a very crucial role in determining labor productivity in the production process at the macro level.

\section{Acknowledgements}

The authors thank the anonymous reviewers and the editors of the Journal for their helpful comments and suggestions.

\section{References}

Buckley, P. J., Clegg, J., \& Wang C. (2002). The Impact of Inward FDI on the Performance of Chinese Manufacturing Firms. Journal of International Business Studies, 33(4), 637-655. http://dx.doi.org/10.1057/palgrave.jibs.8491037

Carrillo, F. J. (2002). Capital Systems: Implications for a Global Knowledge Agenda. Journal of Knowledge Management, 6(4), 379-399. http://dx.doi.org/10.1108/13673270210440884

Clarke, T (2001). The Knowledge Economy. Education + Training, 43(4/5), 189-196.

Dahlman, C. J., \& Aubert, J. (2001). China and the Knowledge Economy: Seizing the 21st Century. WBI Development Studies, The World Bank, Washington, D. C.

Gilboy, G. (2004). The Myth behind China's Miracle. Foreign Affairs, 83(4), 33-48.

Hall, R. E., \& Jones, C. I. (1999). Why Do Some Countries Produce So Much More Output per Worker than Others? Quarterly Journal of Economics, 114(1), 83-116.

Huang, C., \& Soete L. (2007). The Global Challenges of the Knowledge Economy: China and the EU. UNU-MERIT Working Paper Series No. 2007-28, United Nations University, Maastricht Economic and Social Research and Training Centre on Innovation and Technology.

Jiang, Y. (2011). Economic Environment, Technology Diffusion, and Growth of Regional Total Factor Productivity in China. Journal of Chinese Economic and Business Studies, 9(2), 151-161. http://dx.doi.org/10.1080/14765284.2011.568684

Laszlo, K. C., \& Laszlo A. (2007). Fostering a Sustainable Learning Society through Knowledge Based Development. Systems Research and Behavioral Science, 24(5), 493-503. http://dx.doi.org/10.1002/sres.850

Lever, W. F. (2002). Correlating the Knowledge-Base of Cities with Economic Growth. Urban Studies, 39(5/6), 859-870. http://dx.doi.org/10.1080/00420980220128345

Liu, X., \& Wang C. (2003). Does Foreign Direct Investment Facilitate Technological Progress? Evidence from Chinese Industries. Research Policy, 32(6), 945-953. http://dx.doi.org/10.1016/S0048-7333(02)00094-X

Ovalle, M. D. R. G., Marquez, J. A. A., \& Salomon S. D. M. (2004). A Compilation of Resources on Knowledge Cities and Knowledge-Based Development. Journal of Knowledge Management, 8(5), 107-127.

Sheehan, P. (1999). The Global Knowledge Economy: Challenges for China's Development. CSES Working Paper No. 15, Victoria University, Melbourne, Australia.

\section{(c) EY}

This work is licensed under a Creative Commons Attribution 3.0 License. 